\title{
Nutrition in conflict situations
}

\author{
Florence Egal* \\ Food and Nutrition Division, FAO, Rome, Italy
}

\begin{abstract}
High prevalence of malnutrition is often linked to conflict situations. Conflicts affect local livelihoods, impair productive activities and limit access to safe foods and basic services. Strategies to protect and promote nutrition of affected households and communities must be based on an understanding of this impact. While nutrition rehabilitation and food aid are clearly essential to preserve lives in the short run, they cannot provide lasting solutions. Impaired nutritional status ultimately reflects livelihood degradation but anthropometric indicators cannot be used to target timely interventions. They should be combined with simple indicators of food consumption which react more quickly to both crisis and relief/rehabilitation interventions. Local institutions should be encouraged to share information and build causality models of malnutrition for the main vulnerable livelihood groups as a basis for an integrated response. A communication component will systematically be needed to allow people to make informed decisions in a context with which they are often not familiar.
\end{abstract}

Nutrition intervention: Conflict situations: Food security

While increased attention has been given recently to micronutrient deficiencies in crisis situations, much remains to be done in terms of food safety: people who face constraints in accessing and preparing the food they need may be obliged to eat toxic or contaminated foods.

Conflicts usually occur in contexts of chronic food insecurity and marginalization. It is therefore important to identify at-risk zones with a view to prevent conflict, strengthen resilience and ensure preparedness. Promoting food security, nutrition and livelihoods in such areas should be seen as the foundation for peace.

In September 2000, all 191 UN member states pledged to meet the Millennium Development Goals and in particular the first Goal, 'Eradicate extreme poverty and hunger', which aims to reduce by half the proportion of people who suffer from hunger by 2015 . This will not be achieved unless priority is given to deal effectively with conflict situations, from prevention and preparedness through relief to rehabilitation and recovery.

High prevalences of malnutrition can usually be found in conflict situations. As a consequence, nutrition interventions have become a standard component of the humanitarian response in complex emergencies, and nutritionists play an active role in the field. The objective of the present paper is to advocate for a broadened vision of nutrition support in conflict situations as a means to strengthen the resilience of at-risk households and the capacity of local institutions and thus contribute to a culture of peace.

Conflicts are bound to affect the food and nutrition situation of the local population in a variety of ways. Productive activities are disrupted, food stores are looted or destroyed, livestock is slaughtered, insecurity and landmines prevent people from growing crops, people hiding in the forests are obliged to feed on wild foods, host families share their resources with displaced relatives or orphans, market supply and prices are affected and all of the above undermine household food security. People may have to leave their homes and live in unhealthy surroundings and overcrowded shelters. Health services may no longer be available or people stop using them. Families are separated, adults traumatized and childcare is affected. As a result, the combination of poor and/or unsafe dietary intake with disease is likely to lead to increased malnutrition (United Nations Standing Committee on Nutrition, 2000).

The impact of conflict on a given household or population group will depend on its nature, and therefore on how it affects the livelihood of that household or group, on the socio-economic vulnerability of the household and on the 'coping strategies' adopted to face the crisis. It will therefore change with time and the full nutrition impact may actually be observed months after the beginning of the crisis or a specific episode. The measures adopted to assist the affected population (e.g. distribution of food aid) can also have longerterm or unintended impacts both on the beneficiary group and/or other population groups.

Nutrition is widely used in conflict situations as an argument to raise funds for relief projects (food aid, health, food and agriculture). Classic emergency nutrition interventions include general food distribution, anthropometric surveys (increasingly requested by donors to justify their support), supplementary feeding, micronutrient supplementation and nutrition rehabilitation services, as well as some nutrition education associated to health services (United Nations High Commissioner for Refugees, 1995). While these are essential to save lives, they cannot provide sustainable solutions to the causes of malnutrition. They sometimes generate unintended negative impacts at local level. 
Designing appropriate nutrition interventions that take into consideration the specificities of the context, crisis and population, and tackle both immediate and more long-term needs through a holistic approach, requires adequate needs assessments. There is an increasing consensus that nutrition assessments should be expanded to ensure a better understanding of the impact of the conflict (who is affected? how/why are they affected? how do they 'cope'? how is the situation likely to evolve? who is doing what about the problem?) for appropriate responses to be developed. Such assessments - which would thus be expanded to food security, nutrition and livelihoods assessments - should therefore include: (i) the identification of vulnerable livelihood groups; (ii) for each group, a simple food consumption assessment, a causality model of malnutrition and an inventory of coping mechanisms; and (iii) an institutional analysis of local and national actors (government and non-governmental organizations (NGO), both local and international; Collins, 2001).

Impaired nutritional status in conflict situations usually reflects severe livelihood degradation and justifies immediate household and/or community relief interventions. However, one should not wait for clinical signs of malnutrition and changes in anthropometric indicators to target interventions. A basic understanding of the determinants of nutrition and the effect of conflict for a given population group, associated with simple indicators of food consumption (which are the first to react to both crisis and relief/rehabilitation interventions), provide a better basis for action (Salama et al. 2004).

The depth of this assessment will clearly depend on the time and resources available, as well as the security context. Early rapid assessments should eventually be complemented, validated and collated with other relevant information as part of a food security, nutrition and livelihoods information system.

Methodologies will, of course, need to be chosen and adapted accordingly and will build upon and complement qualitative methods (such as purpose sampling and semi-structured interviews with focus groups and key resource people). It is essential that assessments involve both local institutions (governments and NGO) and representatives of the affected population. A mix of external consultants and local staff is therefore advisable to facilitate the pooling of available information and local contacts, as well as strengthen local response (United Nations High Commissioner for Refugees, 2004; Young et al. 2004).

Vulnerable livelihood assessments will logically result in identifying a combination of inter-sectoral activities to deal with the constraints and opportunities identified. Participatory planning with relevant stakeholders at local and national level is essential to the development of realistic strategies to protect and promote food security, nutrition and livelihoods and their appropriation by local actors.

Such strategies should build upon existing activities and, in particular, self-targeting nutrition rehabilitation activities and supplementary feeding programmes: outreach programmes would help to protect and strengthen food security, nutrition and livelihoods at community level and prevent new admissions or re-admissions. Nutrition education and communication should be systematically associated to ensure that households can make the best of available resources in often drastically different living conditions. Care is usually a major problem in conflict situations and systematic attention and priority should be given to promote and/or strengthen community-based care systems. While increased attention has been recently given to micronutrient deficiencies in crisis situations, much remains to be done in terms of food safety: people who face constraints in accessing and preparing the food they need may be obliged to eat toxic or contaminated foods for want of an alternative.

The present paper therefore argues for an expanded role for nutritionists operating in conflict situations. Given the close association between food insecurity, malnutrition and poverty, nutritionists can assist in the identification of vulnerable population groups, of the constraints they are facing and the coping strategies they are adopting. They can therefore assist in the identification and design of interventions to improve food security, health and care and in the incorporation of nutrition considerations in emergency relief and rehabilitation projects and programmes. They can contribute to assessing, understanding and monitoring the food and nutrition situation, thereby contributing to monitor the impact of relief interventions.

This approach can be applied and adapted at all stages of and throughout 'the emergency cycle' (prevention and preparedness, relief, rehabilitation and recovery), and encompasses all vulnerable livelihood groups within a given geographical area. Food security, nutrition and livelihoods projects can therefore be instrumental in bridging the somewhat artificial gap between the emergency cycle stages, as well as between development and emergency processes at local level. They also contribute to integrating interventions from different sectors, strengthening capacity and coordination of local institutions, and raising awareness of and training and educating the local population and institutions on food and nutrition related matters.

In this new perspective, nutritionists in conflict situations should work towards strengthening the capacity of government institutions through effective collaboration with competent NGO (which can function as national consultants); reviewing, documenting and disseminating relevant local experience; facilitating local inter-institutional planning; promoting integrated interventions at community level; disseminating information and training; facilitating the delivery of requested technical assistance; and ensuring that specific attention is given to assisting orphans, handicapped and traumatized people, as well as the families they live with (Young et al. 2004).

This new role would call for a shift from a scientific/dietetic approach to nutrition to a process approach where nutritionists would facilitate the development of integrated pro-poor strategies at local level, add value to sectoral projects and programmes, and lobby for a systematic integration of 'social' and 'productive' projects and programmes (health and agriculture in particular) at a local level, on the one hand, and 'humanitarian' and development activities on the other hand.

Nutrition in conflicts should be addressed from a rights-based perspective. It is an opportunity for change as conflict situations generate demand, funding and visibility. However, NGO, international organizations (and in particular UN agencies such as FAO, UNICEF and the World Food Programme) and donors should be held accountable for developing and supporting common strategies to protect and promote household food security, nutrition and livelihoods, which in turn would constitute 
the most effective exit strategy for emergency relief projects and programmes. Active lobbying should also be made to promote household food security, nutrition and livelihood programmes in at-risk areas (ensuring appropriate, equitable and sustainable use of natural resources, strengthening the resilience of vulnerable households and building up capacity of local institutions), as the best means to ensure peace.

\section{References}

Collins S (2001) Changing the way we address severe malnutrition during famine. Lancet 358, 9280, 498-501.
Salama P, Spiegel P, Talley L \& Waldman R (2004) Lessons learned from complex emergencies over past decade. Lancet 364, $1801-1813$.

United Nations High Commissioner for Refugees (1995) Commodity Distribution, A Practical Guide for Field Staff. Geneva: UNHCR.

United Nations High Commissioner for Refugees (2004) Integration of HIV/AIDS Activities with Food and Nutrition Support in Refugee Settings: Specific Programme Strategies. Geneva: UNHCR.

United Nations Standing Committee on Nutrition (2000) Report of the Meeting of the Working Group on Nutrition in Emergencies. http://www.unsystem.org/scn/Publications/AnnualMeeting/SCN26/ nutritionemergencies.htm

Young H, Borrel A, Holland D \& Salama P (2004) Public nutrition in complex emergencies. Lancet 364, 1899-1909. 